\title{
Sacroiliac joint pain: burden of disease
}

\author{
Daniel Cher ${ }^{1}$ \\ David Polly ${ }^{2}$ \\ Sigurd Berven ${ }^{3}$ \\ 'SI-BONE, Inc., San Jose, CA, \\ USA; ${ }^{2}$ Department of Orthopedic \\ Surgery, University of Minnesota, \\ Minneapolis, MN, USA; ${ }^{3}$ Department \\ of Orthopedic Surgery, University \\ of California San Francisco, \\ San Francisco, CA, USA
}

This article was published in the following Dove Press journal:

Medical Devices: Evidence and Research

12 April 2014

Number of times this article has been viewed

Objectives: The sacroiliac joint (SIJ) is an important and significant cause of low back pain. We sought to quantify the burden of disease attributable to the SIJ.

Methods: The authors compared EuroQol 5D (EQ-5D) and Short Form (SF)-36-based health state utility values derived from the preoperative evaluation of patients with chronic SIJ pain participating in two prospective clinical trials of minimally invasive SIJ fusion versus patients participating in a nationally representative USA cross-sectional survey (National Health Measurement Study [NHMS]). Comparative analyses controlled for age, sex, and oversampling in NHMS. A utility percentile for each SIJ subject was calculated using NHMS as a reference cohort. Finally, SIJ health state utilities were compared with utilities for common medical conditions that were published in a national utility registry.

Results: SIJ patients (number $[\mathrm{n}]=198$ ) had mean SF-6D and EQ-5D utility scores of 0.51 and 0.44 , respectively. Values were significantly depressed $(0.28$ points for the SF-6D utility score and 0.43 points for EQ-5D; both $P<0.0001)$ compared to NHMS controls. SIJ patients were in the lowest deciles for utility compared to the NHMS controls. The SIJ utility values were worse than those of many common, major medical conditions, and similar to those of other common preoperative orthopedic conditions.

Conclusion: Patients with SIJ pain presenting for minimally invasive surgical care have marked impairment in quality of life that is worse than in many chronic health conditions, and this is similar to other orthopedic conditions that are commonly treated surgically. SIJ utility values are in the lowest two deciles when compared to control populations.

Keywords: sacroiliac joint fusion, chronic lower back pain, quality of life, utility assessment, comparative assessments

\section{Introduction}

Chronic lower back pain carries a significant public health burden, with an estimated 83 million well years of life lost every year due to ill health, disability, or early death. ${ }^{1}$ Lower back pain is more burdensome than many other highly impactful conditions, such as cancer and chronic obstructive pulmonary disease (COPD), and it is the sixth most common cause of decrements in global disability-adjusted life years. ${ }^{2}$ In highly developed countries, lower back pain is among the top three causes of years with disability, and the disutility of chronic lower back pain has been rated as high in most countries. ${ }^{2}$

The sacroiliac joint (SIJ) is well recognized as a source of pain in many patients who present with chronic lower back pain. ${ }^{3}$ In two large retrospective reviews of patients referred for the outpatient evaluation of back pain, SIJ pain was a common diagnosis, occurring in $14 \%$ and $22 \%$ of cases, respectively. ${ }^{4,5}$ Among the patients evaluated for
Correspondence: Daniel Cher SI-BONE, Inc., 3055 Olin Avenue, Suite 2200, San Jose, CA 95128 USA

$\mathrm{Tel}+\mathrm{I} 6502695763$

Fax + I 8882434502

Email dcher@si-bone.com 
residual off-center lower back pain after lumbar fusion, the SIJ was diagnosed as the source of pain in approximately $40 \%$ of patients. ${ }^{6,7}$ Treatment options for SIJ pain include physical therapy, ${ }^{8}$ SIJ steroid injections, ${ }^{9,10}$ radiofrequency ablation of the SIJ, ${ }^{11,12}$ and open ${ }^{13}$ or minimally invasive ${ }^{14-18}$ SIJ fusion.

The impact of pain from the SIJ has not been well described. ${ }^{19,20}$ Because the burden of orthopedic disorders on the health economy is high, it is important to define the components of the burden of musculoskeletal disorders for funding and allocation of care. The contribution of the SIJ to the overall burden of lower back pain and the impact of SIJ pain on the health status of affected patients has not been defined. The purpose of this paper is to report the impact of SIJ pain on patients' self-assessments of their health status, and to compare the burden of SIJ pain to the health status of patients derived from a nationally representative cohort of free-living individuals and to other common orthopedic conditions.

\section{Methods}

\section{Cohorts}

Two cohorts were used in this study. The SIJ cohort consists of 198 patients enrolled in two ongoing, prospective, multicenter clinical trials of minimally invasive SIJ fusion (NCT01640353, NCT01681004). ${ }^{21,22}$ To qualify, adult patients between the ages of 21 years and 70 years had to have carefully diagnosed chronic SIJ pain due to degenerative sacroiliitis or sacroiliac joint disruption, as outlined in Table 1. Eligible patients completed Short Form (SF)-36 (SF-36v2 $\left.{ }^{\mathrm{TM}}\right)^{23}$ and EuroQol's EQ-5D ${ }^{24}$ health-related quality of life (HRQoL) questionnaires at baseline and at selected follow-up time points. In one study (NCT01640353), all subjects underwent immediate minimally invasive SIJ fusion using a series of titanium implants. In the other study (NCT01681004), subjects were assigned at random to either immediate minimally invasive SIJ fusion using titanium implants or nonsurgical management (medication optimization, physical therapy, SIJ steroid injection, and/or radiofrequency ablation of the SIJ).

The normal cohort consisted of patients participating in the United States National Health Measurement Study (NHMS), for which datasets are publicly available, ${ }^{25}$ NHMS was designed to compare commonly used preference-based HRQoL instruments (SF-36, ${ }^{23} \mathrm{SF}-6 \mathrm{D},{ }^{26} \mathrm{EQ}-5 \mathrm{D},{ }^{24}$ and other surveys) in an oversampled cross-sectional sample of 3,844 US adults. Interviews were conducted by trained staff at the University of Wisconsin (Madison, WI, USA). Summaries of the distribution of these health measures in the target survey population have been described. ${ }^{27}$

\section{Transformations}

All analyses are based either on SF-36 summary scales (physical component summary [PCS] and mental component summary [MCS]) or transformations of responses to HRQoL surveys into health state utilities. The NHMS dataset contains these transformations for SF-6D and EQ-5D. Transformations for the SIJ cohort were performed similarly, using published transformations. ${ }^{28,29}$

\section{Statistical evaluation}

The NHMS and SIJ cohorts were combined with an additional grouping variable representing the cohorts (SIJ

Table I Key eligibility criteria for SIJ pain

\begin{tabular}{|c|c|}
\hline Inclusion criteria & Exclusion criteria \\
\hline $\begin{array}{l}\text { - Age } 2 \mathrm{I}-70 \text { years at screening } \\
\text { - Pain for at least } 6 \text { months (under the care of a physician) at or close to the posterior } \\
\text { superior iliac spine with possible radiation into the buttocks, posterior thigh, or groin } \\
\text { rated as } \geq 50 \text { on a } 0-100 \text { visual analog scale } \\
\text { - Positive Fortin finger test }{ }^{4 I} \\
\text { - At least three of five positive physical examination maneuvers that stress the } \mathrm{SIJ} \\
\text { - Improvement of at least } 50 \% \text { in pain after image-guided injection of } 0.5 \text { cc of contrast and } \\
\text { up to I.5 cc of local anesthetic (lidocaine, bupivacaine, or ropivacaine) into the target joint. } \\
\text { All blocks were confirmed fluoroscopically by observation of contrast flowing into the } \\
\text { target joint. Patients rated pain on a } 0-10 \text { numeric rating scale both immediately prior to } \\
\text { the diagnostic block and at } 30 \text { minutes and } 60 \text { minutes after the block } \\
\text { - Diagnosis of either degenerative sacroiliitis (based on a history or prior lumbar spine fusion } \\
\text { or radiographic signs of degeneration in the SIJ) or sacroiliac joint disruption (based on } \\
\text { radiographic widening of the target } \mathrm{SI} \text { joint, or leakage of contrast on a diagnostic arthrogram) } \\
\text { - Oswestry Disability Index score of at least } 30 \%\end{array}$ & $\begin{array}{l}\text { - Severe residual back pain due to other causes } \\
\text { - Other sacroiliac pathology (for example, } \\
\text { tumor, fracture, inflammatory spondylitis) } \\
\text { - Recent ( }<\text { I year ago) major trauma } \\
\text { - Diagnosed or suspected osteoporosis } \\
\text { - Pregnancy } \\
\text { - Known or suspected drug abuse } \\
\text { - Uncontrolled psychiatric disease }\end{array}$ \\
\hline
\end{tabular}

Note: See NCT01640353, NCT0168I004 on clinicaltrials.gov for details. ${ }^{21,22}$

Abbreviation: SIJ, sacroiliac joint. 
cohort or NHMS). Mean values were calculated across the NHMS age groups and sexes using SAS PROC SURVEYMEANS (SAS Institute Inc., Cary, NC, USA), which accounts for both oversampling and sampling strata. SAS PROC SURVEYREG was used to model mean PCS, MCS, SF-6D, and EQ-5D values, controlling for age group and sex, age $\times$ sex interaction, and accounting for oversampling.

An alternative approach to estimating the health impact is calculating each SIJ patient's percentile for a selected index using the NHMS cohort as a reference standard. That is, kernel density estimates of the NHMS values for SF-36 PCS, MCS, SF-6D, and the EQ-5D index were produced by age group and sex, taking into account survey sampling weights. Then, for each SIJ subject, the corresponding age- and sexmatched NHMS kernel density estimate function was used to estimate the subject's percentile when compared to the NHMS reference population. The mean percentile for the SIJ cohort is indicative of HRQoL with SIJ pain compared to an age- and sex-matched reference standard; a mean percentile of $5 \%$ indicates that the quality of life of patients with SIJ pain is worse than 95 out of 100 age- and sex-matched peers. In a randomly selected subset of the reference population, the median percentile estimate should be 50. Therefore, percentiles for the SIJ population were compared against a median of 50 using a Wilcoxon test.

\section{Comparison to other illnesses}

To put the quality of life impact of SIJ pain into perspective, we compared the reported SIJ utility values to the published utility values for other common medical and surgical disorders. Estimates of the utility of other common medical and surgical disorders were taken from entries in the CostEffectiveness Analysis Registry, ${ }^{30}$ a utility clearinghouse overseen by the Center for the Evaluation of Value and Risk in Health (Tufts Medical Center, Boston, MA, USA). Calculations were performed using SAS (version 9.0; SAS Institute Inc., Cary, NC, USA) and R. ${ }^{31}$

\section{Results}

The study included 198 patients with SIJ pain and 3,844 people in the NHMS normal cohort. Compared to the NHMS normal

Table 2 Age and sex distributions by cohort

\begin{tabular}{llll}
\hline Characteristic & NHMS & SIJ & P-value \\
& N=3,844 & N=1 98 & \\
\hline Age, mean (SD) & $54.3($ I3.5) & 5 I.6 (II.5) & $<0.000$ I \\
\% female & $2,203(57.3 \%)$ & I $34(67.7 \%)$ & $<0.000$ I \\
\hline
\end{tabular}

Abbreviations: NHMS, National Health Measurement Study; N, number; SIJ, sacroiliac joint; SD, standard deviation. cohort, clinical trial subjects with diagnosed SIJ pain were somewhat younger and more likely to be women (Table 2). Unadjusted mean SF-36 subdomain values were lower in the SIJ cohort compared to the NHMS cohort (Table 3 and Figure 1). Controlling for the differences in age and sex between the two cohorts, the mean HRQoL summary values were substantially lower in the SIJ cohort compared to the normal cohort (Table 4): mean SF-36 PCS and MCS values were 17.8 and 14.3 points lower in the SIJ group compared to normals, respectively; the mean SF-6D and EQ-5D index utility scores were depressed by 0.28 and 0.43 points, respectively, compared to normals. All differences were statistically significant.

To put these figures into perspective, Figure 2 shows age- and sex-matched individual utility values in the SIJ cohort compared with the kernel density estimates for SF-36 PCS, SF-36 MCS, SF-6D, and EQ-5D. Each plot shows the kernel density estimates for the reference NHMS cohort as a smoothed curve and the distribution of individual scores or utility values in the SIJ cohort as dot plot histograms for each combination of age and sex. As expected, density plots for the reference cohort - especially for SF-36 PCS - are sensitive to age, with a broadening and leftward shift in the older ages. For each measurement, values in the SIJ cohort were substantially lower and fell in the lower tails of the NHMS kernel densities, indicating poor health compared to the reference population. For each member of the SIJ cohort, the age- and sex-specific percentile was determined. For all four health state measurements, the age- and sex-adjusted percentiles for the SIJ patients (Figure 2 and Table 5) were low (10th-20th percentiles across age groups), especially for SF-36 and EQ-5D, indicating poor physical health compared to the reference standard. The SIJ cohort percentiles were statistically below the 50th percentile for all measures $(P<0.0001$, Wilcoxon test $)$.

Table 3 SF-36 values in SIJ cohort compared to NHMS normals

\begin{tabular}{lll}
\hline $\begin{array}{l}\text { SF-36 } \\
\text { subdomain }\end{array}$ & Mean $(95 \% \mathrm{CI})^{*}$ \\
\cline { 2 - 3 } & NHMS & SIJ cohort \\
\hline PF & $84.9(83.8-86)$ & $23.4(21.2-25.7)$ \\
RP & $81.1(80-82.3)$ & $21.9(19.3-24.5)$ \\
BP & $72.9(71.7-74.1)$ & $21.0(19.3-22.7)$ \\
GH & $71.0(69.9-72.2)$ & $59.6(56.7-62.4)$ \\
VT & $65.7(64.8-66.7)$ & $30.7(28.1-33.3)$ \\
SF & $87.4(86.4-88.4)$ & $35.7(32.7-38.8)$ \\
RE & $90.5(89.6-91.4)$ & $42.2(38.0-46.4)$ \\
MH & $82.6(81.8-83.3)$ & $55.1(52.1-58.0)$ \\
\hline
\end{tabular}

Notes: *Calculated with SAS PROC ANSSURVEYMEANS (SAS Institute Inc., Cary, NC, USA); SF-36 subdomains include PF, RP, BP, GH, MH, RE, SF, and VT.

Abbreviations: SF-36, Short Form-36; NHMS, National Health Measurement Study; Cl, confidence interval; SIJ, sacroiliac joint; PF, physical function; RP, role physical; BP, bodily pain; GH, general health; VT, vitality; SF, social function; RE, role emotional; $\mathrm{MH}$, mental health. 


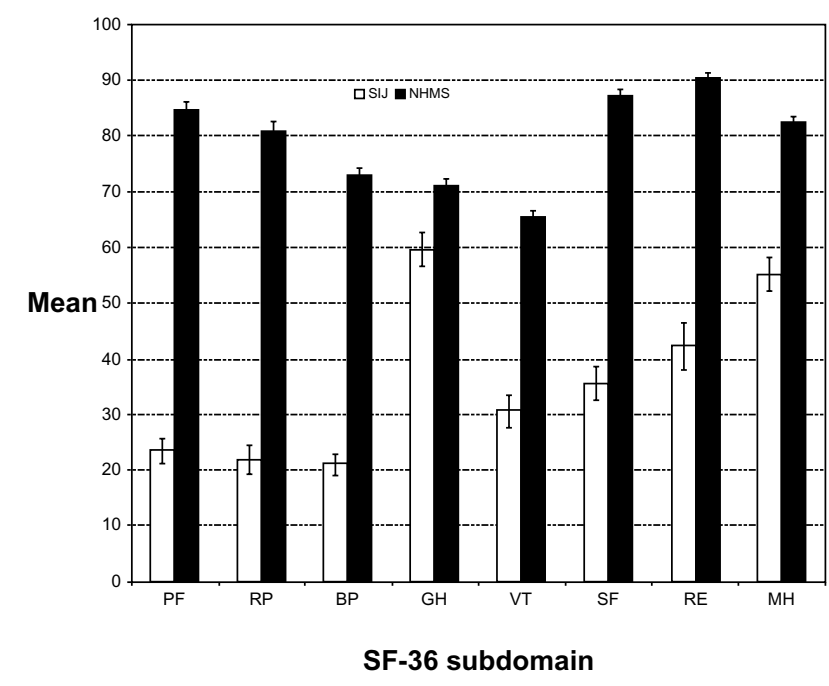

Figure I Mean (unadjusted) SF-36 subdomain values in the SIJ cohort (white) versus the NHMS cohort (black).

Abbreviations: SIJ, sacroiliac joint; NHMS, National Health Measurement Study; PF, physical function; RP, role physical; BP, bodily pain; GH, general health; VT, vitality; SF, social function; RE, role emotional; $\mathrm{MH}$, mental health; SF-36, Short Form-36.

Finally, to put SIJ pain into perspective, the utility values shown in Table 4 were compared with the utility estimates entered into the Cost-Effectiveness Analysis Registry for selected major conditions (Figure 3). The impact of SIJ pain on quality of life appears to fall into the spectrum of the disorders that are severe and have a major impact on HRQoL, indicating that SIJ pathology has a similar impact when compared to other severe disorders.

\section{Discussion}

Our analysis shows that patients with SIJ pain report significant compromise of their health status as compared with normal controls, and when compared with other common medical and surgical conditions. SIJ pain results in a high burden of disease, with an estimated disutility of approximately 0.5 QALYs (quality-adjusted life years). The study used responses to two commonly used HRQoL surveys (SF-36 and EQ-5D) along with well-accepted utility transformations, both of which arrived at similar results. This convergence of information increases the validity of the estimation of the impact of SIJ problems on health. The impact of SIJ pain on HRQoL was high, with marked, clinically significant decrements in health associated with an SIJ pain diagnosis. Compared to nationally representative age- and sex-matched peers, patients with SIJ pain had a quality of life in the 20th percentile or less.

The burden of SIJ pain appears to be higher than in many common medical conditions that are considered to be very disabling (including COPD, coronary heart disease, angina, asthma, and mild heart failure), and it is roughly equivalent to that of chronic depression or severe COPD, and slightly less than that of decompensated liver cirrhosis, lumbar stenosis, or severe Parkinson's disease. Importantly, the impact of SIJ pain appears to be similar to that of other prominent orthopedic surgical conditions, such as hip osteoarthritis, degenerative spondylolisthesis, spinal stenosis, and knee osteoarthritis, all of which are well recognized as significantly debilitating conditions.

The prevalence of SIJ pain in the US is not known, but it can be estimated. SIJ pain, a subtype of lower back pain, could represent up to $15 \%$ of all patients seen in outpatient clinics with chronic lower back pain. ${ }^{5}$ The prevalence of lower back pain in the US has been reported variably and is in the range of $19 \%-29 \%,{ }^{32-34}$ and this number may be rising. ${ }^{35}$ With 234 million adults in the US, ${ }^{36}$ the national burden of SIJ pain could be as high as $234,000,000 \times 29 \%$ $\times 15 \%$, or 10 million. This large number, combined with the substantial impact on quality of life, indicates that SIJ pain imposes a large health burden. Although based on rough estimates, these estimates may be acceptable from a health policy perspective in the absence of more precise data. As shown by our analyses, SIJ pain has a significant impact on affected populations; moreover, SIJ pain is a common cause of chronic lower back pain, ${ }^{5}$ a ubiquitous disease. Therefore, the burden of SIJ pain is high, and the disorder should be a priority for further research and treatment.

Table 4 Mean $(95 \% \mathrm{Cl})$ measures by group and decrement in quality of life measures, controlling for age, sex, age $\times$ sex interaction, and sampling

\begin{tabular}{lllll}
\hline Measure & Cohort & & Decrement* & P-value \\
\cline { 2 - 4 } & NHMS & SIJ & $17.82(16.89-18.74)$ & $<0.0001$ \\
\hline SF-36 PCS & $49.23(48.74-49.70)$ & $3 I .80(31.06-32.54)$ & $14.25(12.6 I-15.89)$ & $<0.000$ I \\
SF-36 MCS & $53.78(53.35-54.20)$ & $39.24(37.67-40.82)$ & $0.277(0.264-0.290)$ & $<0.000$ I \\
SF-6D utility & $0.789(0.782-0.796)$ & $0.5 I 2(0.502-0.522)$ & $0.427(0.399-0.454)$ & $<0.000$ I \\
EQ-5D index & $0.868(0.86 I-0.876)$ & $0.442(0.416-0.468)$ &
\end{tabular}

Notes: *Mean $(95 \% \mathrm{Cl})$. Values show the age- and sex-adjusted decrement associated with membership in the SIJ cohort; calculations were performed using SAS PROC SURVEYREG (SAS Institute Inc., Cary, NC, USA).

Abbreviations: Cl, confidence interval; NHMS, National Health Measurement Study; SIJ, sacroiliac joint; SF-36, Short Form-36; PCS, physical component summary; MCS, mental component summary; EQ-5D, EuroQol-5D. 
From an economic perspective, the burden of SIJ disease is similarly high ${ }^{37}$ Annual expenditures in the US for chronic back pain are as much as $\$ 7.4$ billion- $\$ 13.9$ billion in indirect costs and $\$ 12$ billion- $\$ 90$ billion in direct costs, ${ }^{38}$ with total costs exceeding $\$ 100$ billion. ${ }^{39}$ Chronic low back pain is a symptom that encompasses a broad spectrum of specific diagnoses, including lumbar degenerative pathology, deformity, trauma, and tumor. The SIJ is a significant contributor to the prevalence of lower back pain, and patients with SIJ pain are likely to be an important part of the overall economic burden of the disorders that comprise low back pain. Compared to patients without pain, US patients with chronic lower back pain have twice the yearly health expenditures, with total mean direct annual costs of $>\$ 8,000 . .^{40}$ Again, these figures

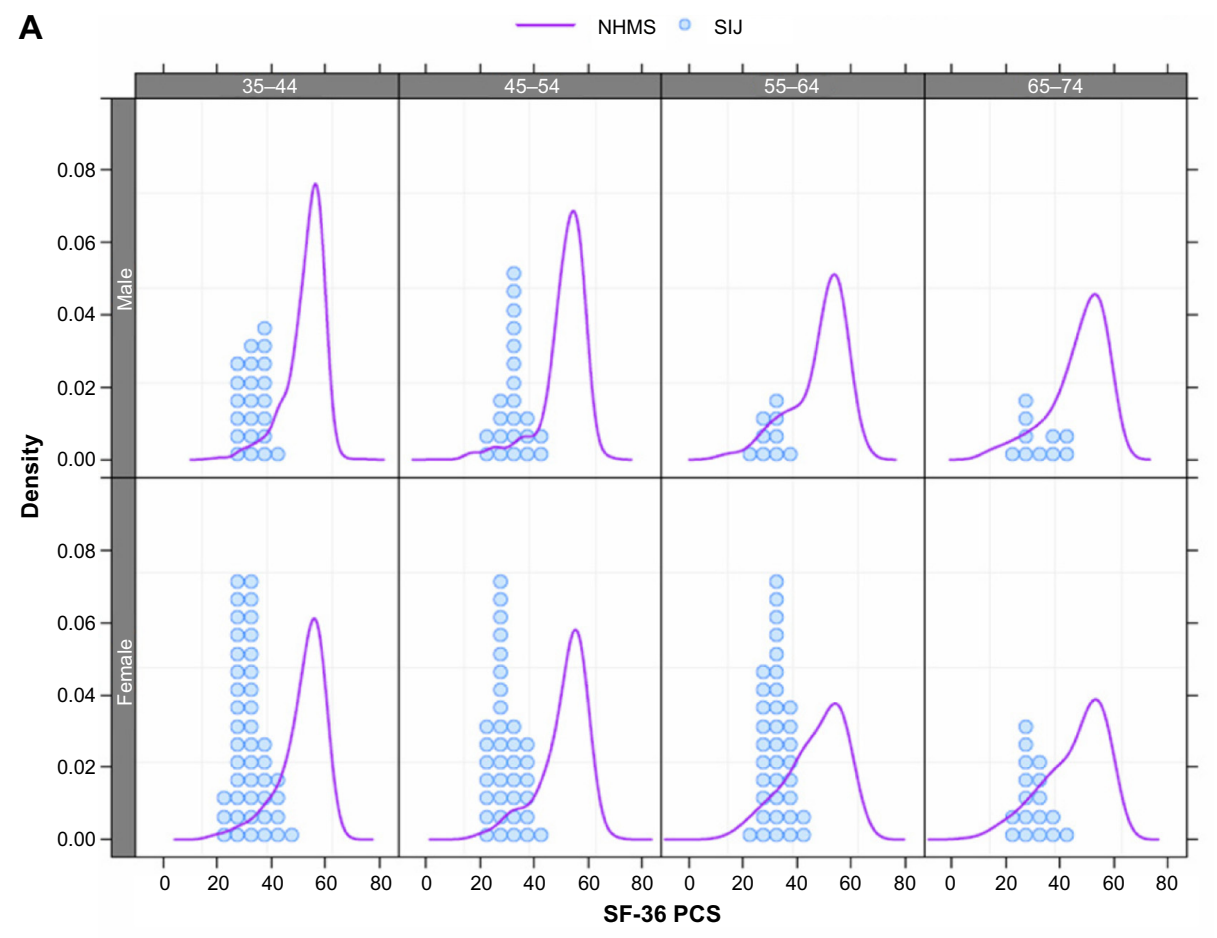

B NHMS $\circ$ SIJ

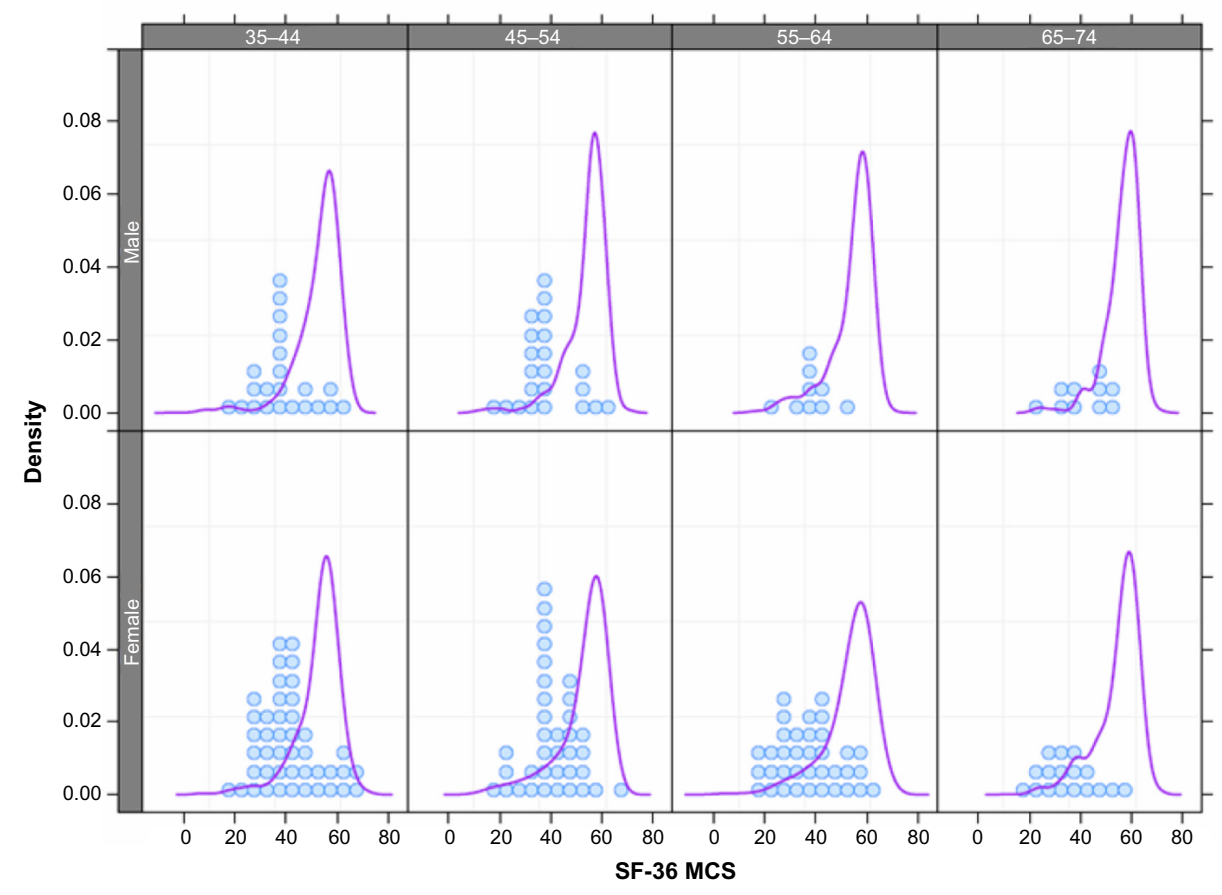

Figure 2 (Continued) 

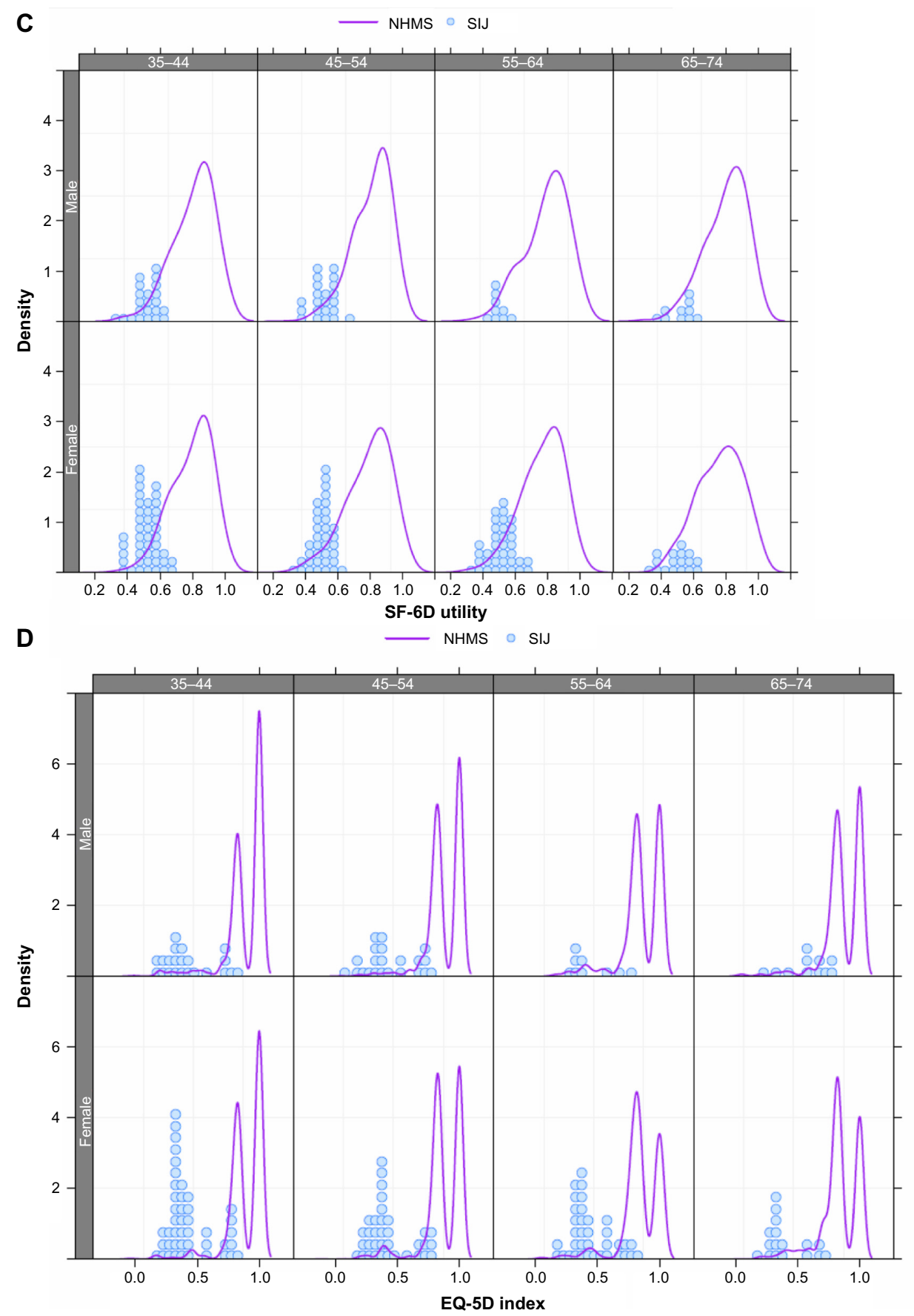

Figure 2 Distribution of value in NHMS cohort (lines) and SIJ cohort (dot plot histogram).

Notes: (A) SF-36 PCS; (B) SF-36 MCS; (C) SF-6D; (D) EQ-5D Index. The EQ-5D shows an expected spike at I.0, indicating very good self-rated health among a large number of normals.

Abbreviations: SIJ, sacroiliac joint; SF-36, Short Form-36; PCS, physical component summary; MCS, mental component summary; EQ-5D, EuroQol-5D; NHMS, National Health Measurement Study.

provide an "order of magnitude" estimate rather than a precise calculation. The NHMS and SIJ cohorts had different age criteria for participation (NHMS: 35 to 89 years old; SIJ: 18 to 70 years old). Nonetheless, the mean age of members of the SIJ cohort was young at 52 . Given an expected retirement age of 65 years, our data suggest that a substantial period of working years can be impacted by SIJ pain, increasing both the direct costs of health care and the indirect care costs due to lost productivity and caregiver burden. This has additional significant societal health care cost implications.

This study has both strengths and limitations. The primary strength of the study is that it compares a highly selected and 
Table 5 Estimated percentile for SIJ cohort compared to the NHMS reference population

\begin{tabular}{|c|c|c|c|c|c|c|c|c|}
\hline \multirow[t]{2}{*}{ Age group } & \multicolumn{2}{|c|}{ SF-36 PCS } & \multicolumn{2}{|c|}{ SF-36 MCS } & \multicolumn{2}{|c|}{ SF-6D utility } & \multicolumn{2}{|c|}{ EQ-5D index } \\
\hline & Female & Male & Female & Male & Female & Male & Female & Male \\
\hline $35-44$ years & 5.8 & 3.2 & 22.3 & 15.0 & 11.7 & 9.7 & 7.8 & 7.7 \\
\hline $45-54$ years & 4.8 & 6.2 & 17.9 & 12.8 & 11.4 & 9.9 & 8.8 & 6.3 \\
\hline $55-64$ years & 14.3 & 9.6 & 16.6 & 10.5 & 16.0 & 10.0 & 11.1 & 10.6 \\
\hline $65-74$ years & 14.0 & 14.3 & 10.3 & 8.5 & 14.0 & 12.9 & 7.9 & 15.2 \\
\hline All & 9.0 & 6.9 & 18.0 & 12.5 & 13.1 & 10.3 & 8.9 & 8.9 \\
\hline
\end{tabular}

Abbreviations: SIJ, sacroiliac joint; NHMS, National Health Measurement Study; SF-36, Short Form-36; PCS, physical component summary; MCS, mental component summary; EQ-5D, EuroQol-5D.

homogeneous patient population (patients eligible for two multicenter clinical trials of minimally invasive SIJ fusion) to members of a free-living nationally representative cohort (NHMS). The primary limitation of the study is that the target patient population may represent the most severe end of the spectrum of SIJ disease, since all trial participants were candidates for SIJ fusion. It should be noted, however, that health state estimates for other orthopedic conditions shown in Figure 3 (hip and knee osteoarthritis, degenerative spondylolisthesis, and so on) were also estimated in the preoperative setting. A population-based study is also of interest to better reflect the burden of disease within all patients with SI joint pain.

Given its probable high prevalence and demonstrated large impact on HRQoL, SIJ disease carries a very high burden of disease. This burden is greater than that of many common health conditions, is equivalent to the burden of common orthopedic conditions (hip and knee osteoarthritis, degenerative spondylolisthesis, and spinal stenosis), and it is only slightly less than the burden of very severe conditions, such as severe Parkinson's disease, ankylosing spondylitis, and decompensated liver failure. SIJ disease appears to affect patients in their mid-life productive years, resulting in a very high economic burden of disease related to both the number of years of living with the disease, as well as associated limitations on productivity. The significant burden of SIJ disease makes it an excellent target for optimizing therapeutic interventions.

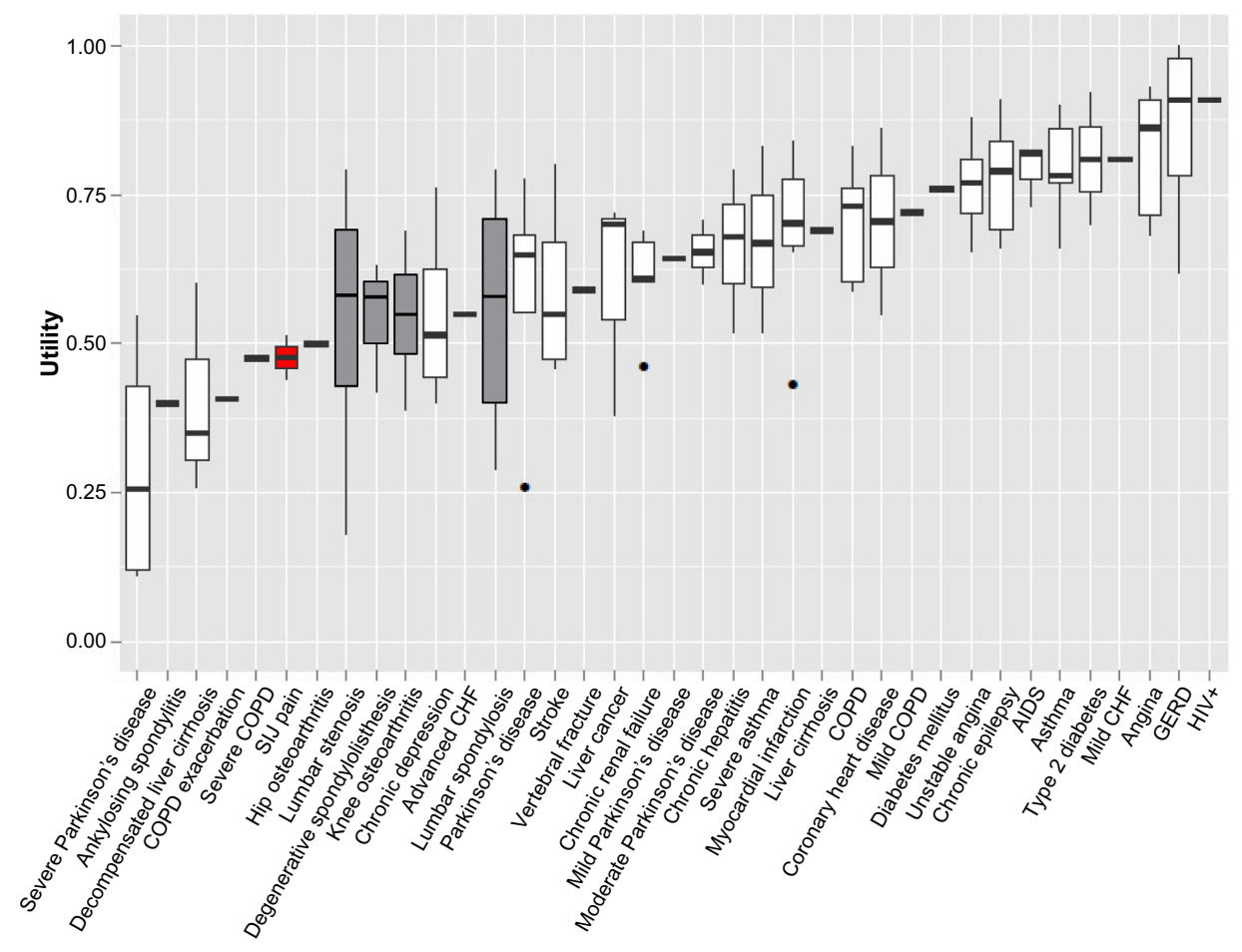

Figure 3 Comparison of utility of SIJ pain with utility values for major diseases, ordered by impact on quality of life.

Abbreviations: COPD, chronic obstructive pulmonary disease; SIJ, sacroiliac joint; CHF, congestive heart failure; AIDS, acquired immunodeficiency syndrome; GERD, gastroesophageal reflux disease; HIV+, human immunodeficiency virus positive. 


\section{Acknowledgment}

The study was sponsored by SI-BONE, Inc. SI-BONE, Inc., sponsored the two prospective clinical trials that provided data on the SIJ patients described herein. The iFuse System is intended for sacroiliac joint fusion for conditions including sacroiliac joint disruptions and degenerative sacroiliitis.

\section{Disclosure}

Daniel Cher is a SI-BONE employee. David Polly is an investigator on a clinical research study sponsored by SIBONE. David Polly and Sigurd Berven have no financial conflict with SI-BONE. The authors report no other conflicts of interest in this work.

\section{References}

1. Murray CJ, Vos T, Lozano R, et al. Disability-adjusted life years (DALYs) for 291 diseases and injuries in 21 regions, 1990-2010: a systematic analysis for the Global Burden of Disease Study 2010. Lancet. 2012;380(9859):2197-2223.

2. Salomon JA, Vos T, Hogan DR, et al. Common values in assessing health outcomes from disease and injury: disability weights measurement study for the Global Burden of Disease Study 2010. Lancet. 2012;380(9859):2129-2143.

3. Manchikanti L, Abdi S, Atluri S, et al. An update of comprehensive evidence-based guidelines for interventional techniques in chronic spinal pain. Part II: guidance and recommendations. Pain Physician. 2013;16(2 Suppl):S49-283.

4. Bernard TN, Kirkaldy-Willis WH. Recognizing specific characteristics of nonspecific low back pain. Clin Orthop Relat Res. 1987;(217): 266-280.

5. Sembrano JN, Polly DW. How often is low back pain not coming from the back? Spine (Phila Pa 1976). 2009;34(1):E27-E32.

6. Liliang PC, Lu K, Liang CL, Tsai YD, Wang KW, Chen HJ. Sacroiliac joint pain after lumbar and lumbosacral fusion: findings using dual sacroiliac joint blocks. Pain Med. 2011;12(4):565-570.

7. DePalma MJ, Ketchum JM, Saullo TR. Etiology of chronic low back pain in patients having undergone lumbar fusion. Pain Med. 2011;12(5): 732-739.

8. Jackson R, Porter K. The pelvis and sacroiliac joint: physical therapy patient management utilizing current evidence. In: Current Concepts of Orthopaedic Physical Therapy. 3rd ed. APTA Independent Study Course. 21.2; 2006.

9. Luukkainen R, Nissilä M, Asikainen E, et al. Periarticular corticosteroid treatment of the sacroiliac joint in patients with seronegative spondylarthropathy. Clin Exp Rheumatol. 1999;17(1):88-90.

10. Luukkainen RK, Wennerstrand PV, Kautiainen HH, Sanila MT, Asikainen EL. Efficacy of periarticular corticosteroid treatment of the sacroiliac joint in non-spondylarthropathic patients with chronic low back pain in the region of the sacroiliac joint. Clin Exp Rheumatol. 2002;20(1):52-54.

11. Cohen SP, Hurley RW, Buckenmaier CC, Kurihara C, Morlando B, Dragovich A. Randomized placebo-controlled study evaluating lateral branch radiofrequency denervation for sacroiliac joint pain. Anesthesiology. 2008;109(2):279-288.

12. Patel N, Gross A, Brown L, Gekht G. A randomized, placebo-controlled study to assess the efficacy of lateral branch neurotomy for chronic sacroiliac joint pain. Pain Med. 2012;13(3):383-398.

13. Buchowski JM, Kebaish KM, Sinkov V, Cohen DB, Sieber AN, Kostuik JP. Functional and radiographic outcome of sacroiliac arthrodesis for the disorders of the sacroiliac joint. Spine J. 2005;5(5):520-528; discussion 529 .
14. Rudolf L. Sacroiliac joint arthrodesis-MIS technique with titanium implants: report of the first 50 patients and outcomes. Open Orthop J. 2012;6:495-502.

15. Sachs D, Capobianco R. Minimally invasive sacroiliac joint fusion: one-year outcomes in 40 patients. Adv Orthop. 2013;2013:536128.

16. Cummings J Jr, Capobianco RA. Minimally invasive sacroiliac joint fusion: one-year outcomes in 18 patients. Ann Surg Innov Res. 2013;7(1):12.

17. Gaetani P, Miotti D, Risso A, et al. Percutaneous arthrodesis of sacro-iliac joint: a pilot study. J Neurosurg Sci. 2013;57(4):297-301.

18. Duhon BS, Cher DJ, Wine KD, Lockstadt H, Kovalsky D, Soo CL. Safety and 6-month effectiveness of minimally invasive sacroiliac joint fusion: a prospective study. Med Devices (Auckl). 2013;6: 219-229.

19. Vos T, Flaxman AD, Naghavi M, et al. Years lived with disability (YLDs) for 1160 sequelae of 289 diseases and injuries 1990-2010: a systematic analysis for the Global Burden of Disease Study 2010. Lancet. 2012;380(9859):2163-2196.

20. Hoy D, Brooks P, Blyth F, Buchbinder R. The Epidemiology of low back pain. Best Pract Res Clin Rheumatol. 2010;24(6):769-781.

21. SI-BONE, Inc. Sacroiliac Joint Fusion With iFuse Implant System (SIFI). Available from: http://clinicaltrials.gov/show/NCT01640353. NLM identifier: NCT01640353. Accessed February 17, 2014.

22. SI-BONE, Inc. Investigation of Sacroiliac Fusion Treatment (INSITE). Available from: http://clinicaltrials.gov/show/NCT01681004. NLM identifier: NCT01681004. Accessed February 17, 2014.

23. Ware JE, Kosinski M. Interpreting SF-36 summary health measures: a response. Qual Life Res. 2001;10(5):405-413; discussion 415-420.

24. Brooks R, Rabin R, de Charro F, editors. The Measurement and Valuation of Health Status Using EQ-5D: A European Perspective: Evidence from the EuroQol BIOMED Research Programme. Dordrecht, The Netherlands: Kluwer Academic Publishers; 2003.

25. National Archive of Computerized Data on Aging [webpage on the Internet]. National Institute on Aging. Available from: https://www. icpsr.umich.edu/icpsrweb/NACDA/studies/23263? groupResults=fals $\mathrm{e} \& \mathrm{q}=\% 22 \mathrm{National}+$ Institute+on+Aging $\% 22 \&$ dataFormat $\% 5 \mathrm{~B} 0 \% 5 \mathrm{D}$ =Delimited. Accessed March 26, 2014.

26. Brazier J, Roberts J, Deverill M. The estimation of a preferencebased measure of health from the SF-36. J Health Econ. 2002;21(2): 271-292.

27. Fryback DG, Dunham NC, Palta M, et al. US norms for six generic health-related quality-of-life indexes from the National Health Measurement study. Med Care. 2007;45(12):1162-1170.

28. Agency for Healthcare Research and Quality [webpage on the Internet] Calculating the US population-based EQ-5D index score. US Rockville, MD: Department of Health and Human Services; 2013. Available from: http://www.ahrq.gov/professionals/clinicians-providers/resources/rice/ EQ5Dscore.html. Accessed October 18, 2013.

29. Hays R [webpage on the Internet]. SF6DUS3.sas. SF-36 SF-6D Convers. Util. May 2, 2002. Available from: http:/gim.med.ucla.edu/ FacultyPages/Hays/UTILS/sf6dus3.sas. Accessed October 15, 2013.

30. Center for the Evaluation of Value and Risk in Health [webpage on the Internet]. Cost-Effectiveness Analysis Registry. Boston, MA: Tufts Medical Center; October 28, 2013. Available from: https://research.tuftsnemc.org/cear4/SearchingtheCEARegistry/SearchtheCEA Registry. aspx. Accessed October 29, 2013.

31. R Core Team, The Institute for Statistics and Mathematics [webpage on the Internet]. R: A language and environment for statistical computing. Vienna, Austria: Wirtschaftsuniversität Wien; 2013. Available from: http://www.R-project.org/. Accessed March 11, 2014.

32. Deyo RA, Mirza SK, Martin BI. Back pain prevalence and visit rates: estimates from US national surveys, 2002. Spine (Phila Pa 1976). 2006;31(23):2724-2727.

33. Hoy D, Bain C, Williams G, et al. A systematic review of the global prevalence of low back pain. Arthritis Rheum. 2012;64(6): 2028-2037. 
34. Loney PL, Stratford PW. The prevalence of low back pain in adults: a methodological review of the literature. Phys Ther. 1999; 79(4):384-396.

35. Freburger JK, Holmes GM, Agans RP, et al. The rising prevalence of chronic low back pain. Arch Intern Med. 2009;169(3):251-258.

36. Howden LM, Meyer JA. Age and Sex Composition: 2010 Census Briefs. Washington, DC: US Department of Commerce, Economics and Statistics Administration; 2011. Available from: http://www.census.gov/ prod/cen2010/briefs/c2010br-03.pdf. Accessed December 15, 2013.

37. Ackerman SJ, Polly Jr DW, Knight T, Holt T, Cummings J. Management of sacroiliac joint disruption and degenerative sacroiliitis with nonoperative care is medical resource-intensive and costly in a United States commercial payer population. Clinicoecon Outcomes Res. 2014;6:63-74.

38. Dagenais S, Caro J, Haldeman S. A systematic review of low back pain cost of illness studies in the United States and internationally. Spine J. 2008;8(1):8-20.
39. Katz JN. Lumbar disc disorders and low-back pain: socioeconomic factors and consequences. J Bone Joint Surg Am. 2006;88 Suppl 2:21-24.

40. Gore M, Sadosky A, Stacey BR, Tai KS, Leslie D. The burden of chronic low back pain: clinical comorbidities, treatment patterns, and health care costs in usual care settings. Spine (Phila Pa 1976). 2012;37(11):E668-E677.

41. Fortin JD, Falco FJ. The Fortin finger test: an indicator of sacroiliac pain. Am J Orthop (Belle Mead NJ). 1997;26(7):477-480.

42. Szadek KM, van der Wurff P, van Tulder MW, Zuurmond WW, Perez RS. Diagnostic validity of criteria for sacroiliac joint pain: a systematic review. J Pain. 2009;10(4):354-368.

\section{Publish your work in this journal}

Medical Devices: Evidence and Research is an international, peerreviewed, open access journal that focuses on the evidence, technology, research, and expert opinion supporting the use and application of medical devices in the diagnosis, treatment and management of clinical conditions and physiological processes. The identification of novel devices and optimal use of existing devices which will lead to improved clinical outcomes and more effective patient management and safety is a key feature. The manuscript management system is completely online and includes a quick and fair peer-review system. Visit http://www. dovepress.com/testimonials.php to read real quotes from authors.

Submit your manuscript here: http://www.dovepress.com/medical-devices-evidence-and-research-journal 